\title{
From observation to aetiology: a case report of a twin fetus-in-fetu and a revisit of the known rarity
}

\author{
Kristine KY Pang, Nicholas SY Chao *, TK Tsang, Betty YT Lau, KY Leung, SH Ting, Michael WY Leung, \\ Kelvin KW Liu
}

\begin{abstract}
A B S T R A C T
A baby girl presented with an antenatal diagnosis of a retroperitoneal tumour. Postnatal imaging suggested that this mass contained two fetiform structures with spine and long bone formation. This teratomatous mass was completely excised at 3 weeks of age. Histology was consistent with twin fetusesin-fetu, revealing two fetiform masses each with an umbilical cord connecting to a common placentalike mass. Despite a difference in the weight of the twin fetuses-in-fetu, the level of organogenesis was identical and corresponded to fetuses of 10 weeks of gestation. Each mass had four limbs, intact skin, rib cage, intestines, anus, ambiguous genitalia, primitive brain tissue and a spine with ganglion cells in the cord. Although considered a mature teratoma in the current World Health Organization classification, the theory of formation from multiple pregnancies has been commonly implied in more recent literature. The true aetiology of this rare condition remains unclear.
\end{abstract}

\section{Introduction}

Fetus-in-fetu is a rare condition with an estimated incidence of 1 in 500000 births. ${ }^{1}$ It was a descriptive term attributed to Meckel circa 1800. The key feature entails well-organised fetal structures in macroscopic pathology, with vertebral columns and, commonly, long bones of the limbs. Variable degree of organogenesis for the lung, liver, intestines, and genitalia has been commonly reported. Although grouped under the entity of teratoma and considered the well-differentiated end of the neoplastic spectrum in the current World Health Organization (WHO) classification, ${ }^{2}$ the true aetiology remains unclear. The theory of formation from monozygotic twins has been commonly implied in the literature. ${ }^{3-5}$

The commonest presentation of this condition was a painless mass lesion with or without pressure symptoms. Prenatal diagnosis was made in nine out of the 88 cases collectively reported by Hoeffel et $\mathrm{al}^{3} \mathrm{We}$, hereby, report the case of a twin fetusin-fetu presenting on antenatal ultrasound, and its histopathology.

\section{Hong Kong Med J 2015;21:80-3}

DOI: 10.12809/hkmj133925

${ }^{1}$ KKY Pang, MB, ChB, MRCSEd

${ }^{1}$ NSY Chao *, FCSHK, FHKAM (Surgery)

${ }^{2}$ TK Tsang, FHKAM (Radiology)

${ }^{3}$ BYT Lau, FHKAM (Obstetrics and Gynaecology)

${ }^{3}$ KY Leung, FHKAM (Obstetrics and Gynaecology)

${ }^{4} \mathrm{SH}$ Ting, MB, BS

${ }^{1}$ MWY Leung, FCSHK, FHKAM (Surgery)

${ }^{5}$ KKW Liu, FCSHK, FHKAM (Surgery)

1 Division of Paediatric Surgery, Department of Surgery, Queen Elizabeth Hospital, Jordan, Hong Kong

${ }^{2}$ Department of Radiology and Imaging, Queen Elizabeth Hospital, Jordan, Hong Kong

${ }^{3}$ Department of Obstetrics and Gynaecology, Queen Elizabeth Hospital, Jordan, Hong Kong

${ }^{4}$ Department of Pathology, Queen Elizabeth Hospital, Jordan, Hong Kong

${ }^{5}$ Division of Paediatric Surgery, Department of Surgery, United Christian

Hospital, Kwun Tong, Hong Kong

* Corresponding author: nickchao@yahoo.com

\section{Case report}

\section{Clinical course}

A Chinese baby girl was admitted to our neonatal unit on the day of birth for antenatal diagnosis of a retroperitoneal mass in November 2010. This was a singleton pregnancy from natural conception, with allegedly normal antenatal ultrasound in early gestation. There were no additional morphology scans during second trimester ultrasound as the mother was a resident of mainland China where she received her obstetric care. Detailed antenatal ultrasound at 37 weeks of maturity showed a $32 \mathrm{~mm}$ x $30 \mathrm{~mm}$ x $30 \mathrm{~mm}$ mass in the left retroperitoneal region of the fetus. There were no other apparent abnormalities, or complicating intestinal or urinary obstruction. The initial differential diagnoses included congenital adrenal tumour and adrenal haemorrhage.

The birth weight of the baby was $4.07 \mathrm{~kg}$. Physical examination showed fullness in the left flank. Targeted ultrasound of the retroperitoneal mass was performed immediately after birth. It 
showed cystic and solid components with areas of ossification within the mass which were suggestive of a teratoma. Abdominal X-ray showed neither dilated bowel nor calcification. Alpha fetoprotein and beta human chorionic gonadotropin levels measured on day 2 of life were normal for age. Clinically, the patient had no evidence of intestinal obstruction and tolerated full feeding soon after birth.

A detailed ultrasound of the abdominal region was performed on day 4 and computed tomography on day 7 (Fig 1). These showed a complex cystic mass between the spleen and the left kidney, with a maximal diameter of $47 \mathrm{~mm}$. Within this single thin-walled cyst, there were two heterogeneous solid masses. Each mass contained a well-ossified spine and two ossified long bones at the caudal end, resembling the configuration of fetal femurs; no cardiac or cranial structures were identifiable.

To rule out the likelihood of neuroblastoma, urine catecholamine profile was performed which turned out to be normal. While imaging pointed to a likely fetus-in-fetu, the remote possibility of a mature teratoma could not be completely ruled out. Thus, a decision was made to perform an early excision of the mass.

Elective laparotomy was performed on day 14. Mobilisation of the colon at the splenic flexure revealed a retroperitoneal mass between the left kidney and left adrenal gland that was supplied by multiple, small feeding vessels from the aorta and left renal artery. After flush-dividing all investing vessels, the mass was resected with an intact capsule. The baby made good recovery from the operation and was discharged uneventfully on postoperative day 22 .

\section{Histopathology}

Pathological section showed two fetiform masses,

\section{從觀察到病因：寄生胎的病例報告及再論此 罕見病症 \\ 彭潔儀、趙式言、曾子勤、劉涴婷、梁國賢、丁信顯、 梁偉業、廖鑑榮}

產前檢查發現一名女嬰呈現腹膜後腫瘤。產後成像顯示這腫瘤有兩個 胎瘤, 其結構包含脊椎和長骨。於女嬰三週歲時把這畸胎瘤完全切 除。此胎瘤的組織學與雙寄生胎一致, 兩個胎瘤均有臍帶連接到同一 個胎盤樣腫塊。儘管雙寄生胎的重量有差異, 器官水平是相同的, 並 相等於妊娠十週的胎兒。每個寄生胎均有四肢、完好的皮膚、肋骨、 腸、肛門、類似外生殖器的器官、原始的腦組織和脊髓脊柱上的神經 節細胞。雖然根據目前世界衛生組織的分類, 這是屬於一個成熟的畸 胎瘤, 近代的文獻卻顯示這是從多胎妊娠形成的。這種罕見病症的真 正原因尚未清楚。

each with an umbilical cord connecting to a single placenta-like mass (Fig 2). The lengths of the fetuses were $37 \mathrm{~mm}$ and $35 \mathrm{~mm}$, respectively. The larger mass contained better developed fetal structures and weighed $14.2 \mathrm{~g}$, while the smaller mass weighed $9.3 \mathrm{~g}$.

Within each of the 'fetuses', vacuolised intestines could be seen in the abdominal cavity but were leading to a non-patent anus (Fig 2, inset). Ambiguous external genitalia were identified in both fetuses. At the cranial end, there was no skull and no skin coverage. The rest of the fetus was covered by intact skin.

Regarding the skeletal formation, there was an ossified segmented spine in each fetus. The spinal cord was identified posterior to the vertebral bodies.

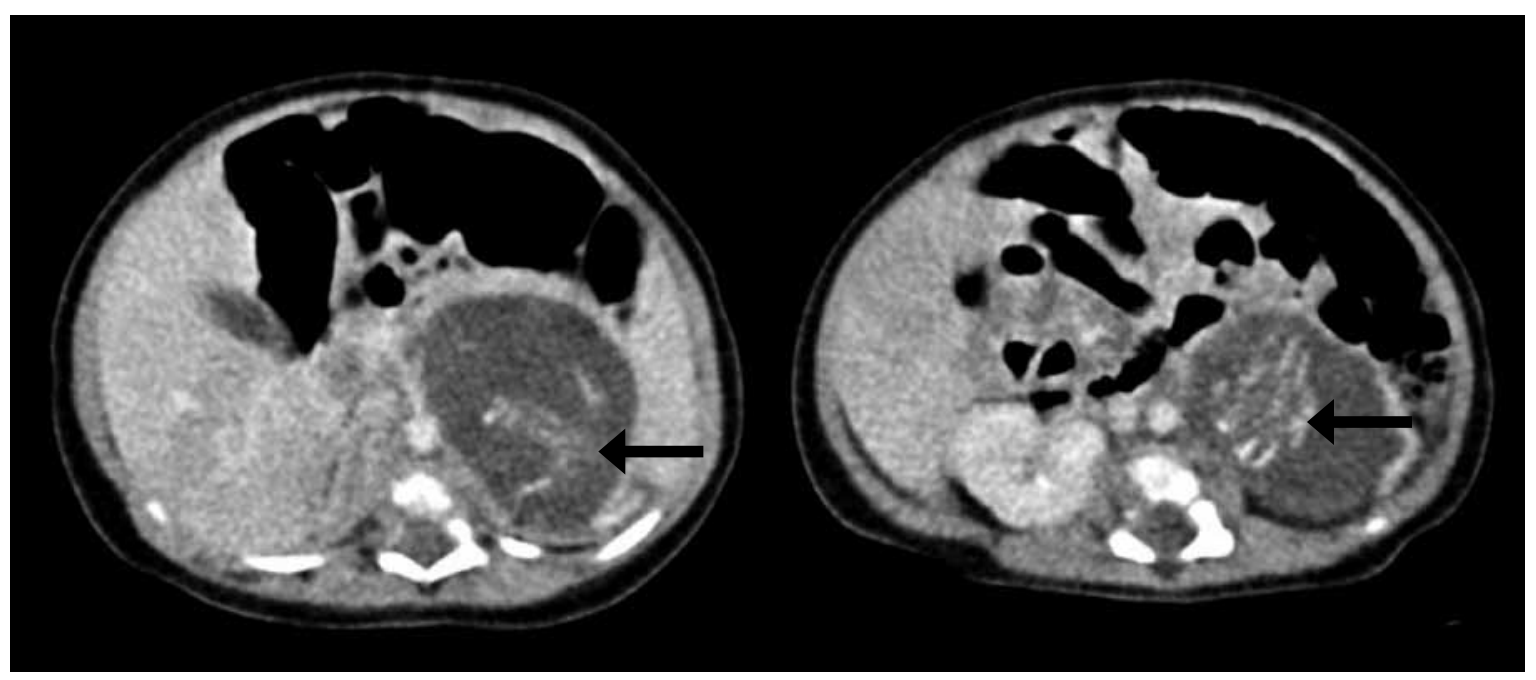

FIG I. Computed tomography showing the spine of each fetus (arrows) 


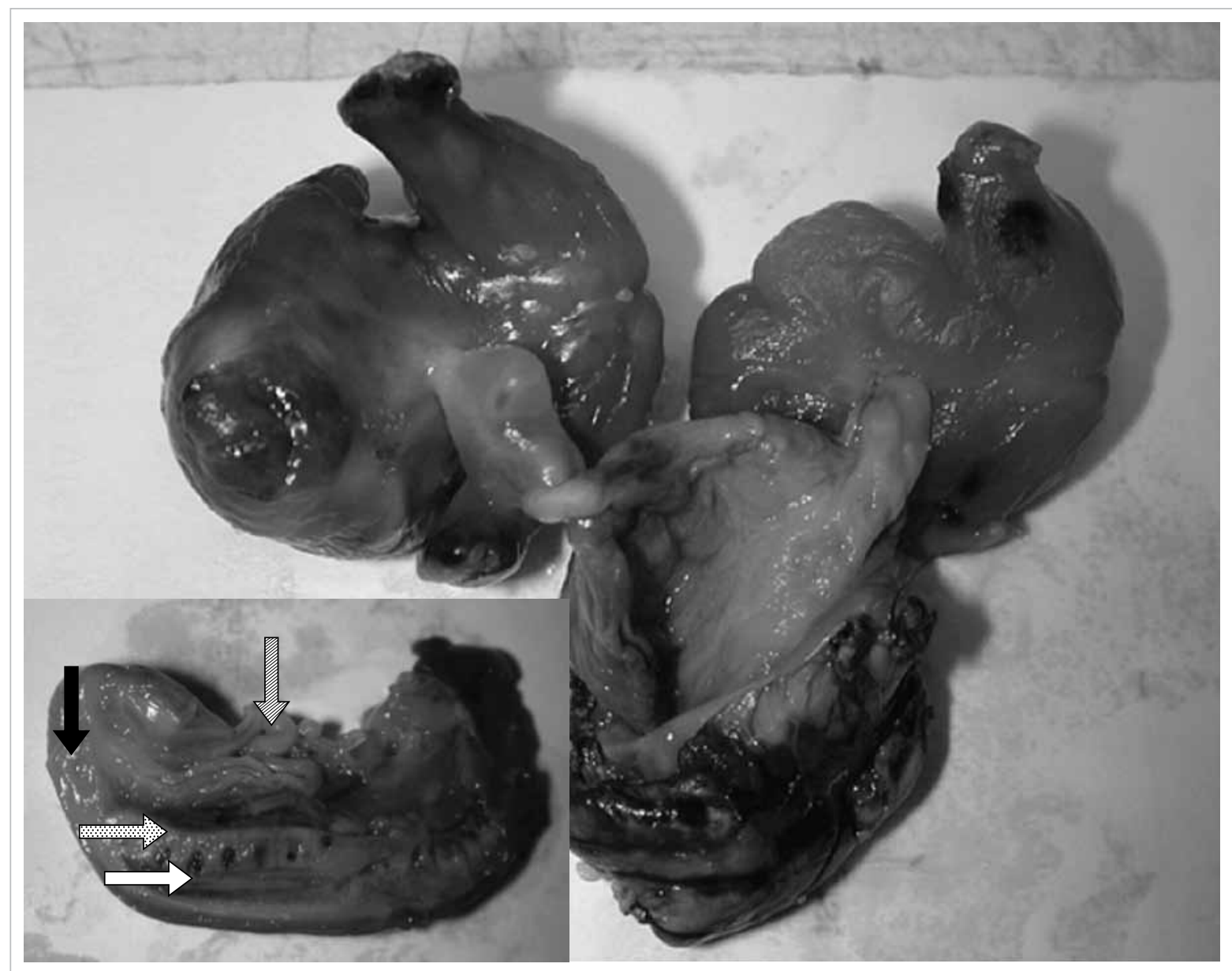

FIG 2. Fetuses-in-fetu with 'umbilical cords'; (inset) mid-sagittal section of the fetus-in-fetu: ossified vertebra was seen containing bone marrow (dotted arrow), the spinal cord (white arrow), the non-patent anus (black arrow), and vacuolised intestines (striped arrows)

A well-developed rib cage with bone and cartilage could be seen in the thoracic region. The pelvic bone and the long bones of the lower limbs were ossified with marrow formation in the centre. Two long bones could be identified in the forearm of the larger fetus. Metatarsals could be identified in both fetuses.

Microscopic examination revealed striated muscles, bones, and cartilages in the limbs. Ganglion cells were present in the spinal cord. The fetuses were covered by organised skin tissue and appendages. Respiratory mucosa was identified in the thoracic region. The intestines in the abdominal cavity were lined by intestinal mucosa. There was disorganised primitive brain tissue in the cranial end of both fetuses.

\section{Discussion}

Fetus-in-fetu is rare, with less than 200 cases reported in the literature. Hui et $\mathrm{al}^{6}$ reported, formally, the first regional case only in 2007. Despite the detailed description in literature, its aetiology and relationship with teratoma remains controversial.

Fetus-in-fetu is currently classified as a variant of mature teratoma. Previous case reports of recurrence after resection with malignant transformation also support this classification, whereby fetus-in-fetu should be the mature end of the spectrum of teratoma. ${ }^{7}$ However, the theory of monozygotic diamniotic twins has been increasingly proposed in the recent literature. ${ }^{3,8}$ Despite the gaining popularity, there is, as yet no concrete evidence to confirm this relationship. Blood group typing, karyotyping, and DNA analysis, when performed in the previously reported cases, always showed identical findings between the fetuses and their hosts. This finding is, however, compatible with both monozygotic multiple pregnancy theory and teratoma theory.

If we consider fetus-in-fetu a result of multiple pregnancy with initial normal embryological development, principles of embryological 
assessment may be considered. By diagnostic criteria, all fetuses-in-fetu possess vertebrae and, therefore, such an embryo should have reached the age of 24 to 25 days, corresponding to a gestational age of 5 weeks. In our case, and indeed in most other reported cases, the caudal neuropores were also closed. This further aged the estimated gestation to 6 weeks before the development was arrested in these presumed parasitic twins. In our case, since digital rays were clearly identified in the hands and feet, the embryonic age should be at least 44 to 46 days, which is 8 weeks by gestation. ${ }^{9}$ If we consider the abundant length of small bowel within the abdominal cavity, the gestational age had likely reached 10 weeks for both of these twin fetuses.

In conventional embryological assessment of aborted products of gestation, size of the fetus can sometimes be smaller than the normal size for embryological age, since the fetuses often undergo a certain period of growth restriction before the actual death. On the other hand, direct measurement of the specimen size may be slightly larger than the ultrasound assessment due to flattening of the tissue after its passage through the cervix. ${ }^{10}$ Interestingly, in the reported literature, a poor correlation has been observed between the level of organogenesis and size of the parasitic fetus. In a review of 87 cases by Hoeffel et $\mathrm{al},{ }^{3}$ there were 10 reported parasitic fetuses weighing over $500 \mathrm{~g}$. The level of organogenesis in these fetuses, however, was immature compared to that of a normal $500 \mathrm{~g}$ fetus or newborn. ${ }^{3}$ If these parasitic fetuses were once products of multiple pregnancies, an interesting conclusion would be that these 'fetuses' continued to grow in size after their arrest in development or, theoretically, the 'death' of fetuses, although the 'death' of such fetuses is always difficult to define in view of their 'acardiac' nature.

With increasing application of assisted reproductive technology, a higher proportion of multiple pregnancies can now be monitored with ultrasound from early gestation. However, to date, there is no longitudinal observation of the evolution of fetus-in-fetu from multiple pregnancies, nor have there been any reported cases arising from assisted pregnancy. Whilst the earliest antenatal diagnosis of this condition in literature was 16 weeks' gestation, ${ }^{11}$ no sequential monitoring of the antenatal history of fetus-in-fetu has been published.

In our case, both the twin parasitic fetuses had body weights, sizes, and fetal structures that corresponded well with a gestational age of 10 weeks. A normal ultrasound during the early antenatal period rather suggests that they might have been tiny parasitic fetuses that had grown slowly with the 'patient' and reached their significant sizes at term, instead of the popular theory of early normal development followed by parasitic inclusion and arrest of growth. Although with limited antenatal documentation, our case report does not support the popular monozygotic multiple pregnancy theory, and favours, by default, the traditional classification into a teratoma.

\section{Conclusion}

Less than 200 cases of twin fetus-in-fetu have been reported worldwide, and, to date, this was only the second regional case report. Although classified by WHO as a variant of mature teratoma, the theory of demised multiple pregnancy has gained much support recently. More evidence is needed to confirm either theory. The widespread use of antenatal ultrasound in early gestation may provide more concrete evidence from longitudinal observation and give light to the aetiology of this intriguing condition.

\section{References}

1. Grant R, Pearn JH. Foetus-in-foetu. Med J Aust 1969;1:1016-20.

2. Scully RE, Young RH, Clement PB. Atlas of tumor pathology, 3rd series, fascicle 23. Washington, DC: Armed Forces Institute of Pathology; 1998: ch13.

3. Hoeffel CC, Nguyen KQ, Phan HT, et al. Fetus in fetu: a case report and literature review. Pediatrics 2000;105:1335-44.

4. Lewis RH. Foetus in foetu and retroperitoneal teratoma. Arch Dis Child 1961;36:220-6.

5. Thrakral CL, Maji DC, Sajwani MJ. Fetus-in-fetu: a case report and review of the literature. J Pediatr Surg 1998;33:1432-4.

6. Hui PW, Lam TP, Chan KL, Lee CP. Fetus in fetu-from prenatal ultrasound and MRI diagnosis to postnatal confirmation. Prenat Diagn 2007;27:657-61.

7. Hopkins KL, Dickson PK, Ball TI, Ricketts RR, O'Shea PA, Abramowsky CR. Fetus-in-fetu with malignant recurrence. J Pediatr Surg 1997;32:1476-9.

8. Mohan H, Chhabra S, Handa U. Fetus-in-fetu: a rare entity. Fetal Diagn Ther 2007;22:195-7.

9. O’Rahilly R, Müller F. Developmental stages in human embryos. Carnegie Institute of Washington; 1987: Publication no. 637.

10. Harkness LN, Rodger M, Baird DT. Morphological and molecular characteristics of living human fetuses between Carnegie stages 7 and 23: ultrasound scanning and direct measurements. Hum Reprod Update 1996;3:25-33.

11. Khatib MO, Deschamps F, Couture A, Giacalone PL, Boulot P. Early prenatal ultrasonographic diagnosis of fetus in fetu [in French]. J Gynecol Obstet Biol Reprod (Paris) 1998;27:438-40. 